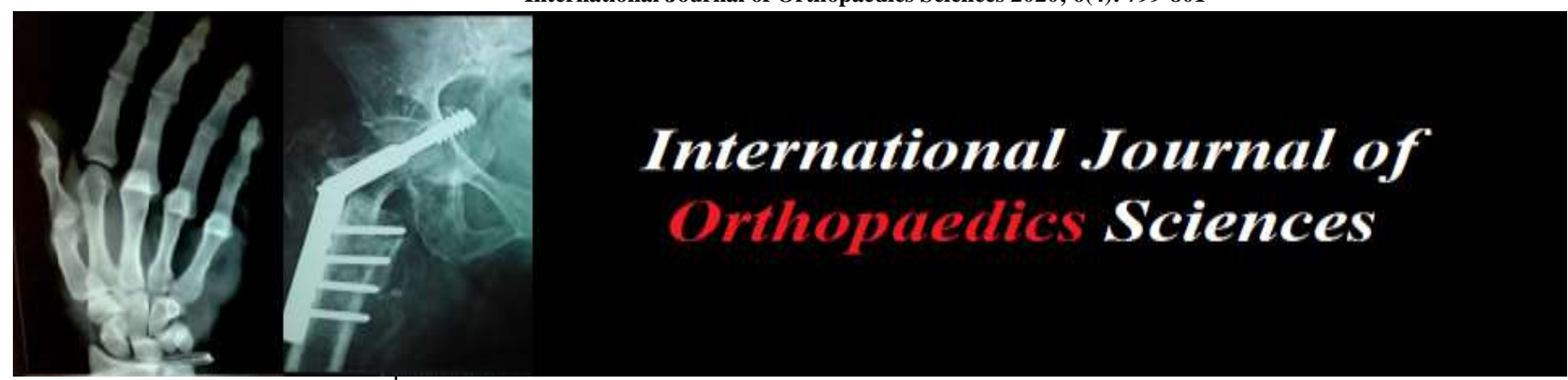

E-ISSN: 2395-1958

P-ISSN: 2706-6630

IJOS 2020; 6(4): 799-801

(C) 2020 IJOS

www.orthopaper.com

Received: 18-08-2020

Accepted: 03-10-2020

Alaa Eddin Obeid

MB Bch BAO, Salmaniya

Medical Complex. Ministry of

Health, Kingdom of Bahrain,

Bahrain

Huda Al-Nasheet

MB Bch BAO, MSc, Salmaniya Medical Complex. Ministry of Health, Kingdom of Bahrain, Bahrain
Corresponding Author: Alaa Eddin Obeid MB Bch BAO, Salmaniya Medical Complex. Ministry of Health, Kingdom of Bahrain, Bahrain

\section{Ultrasonographic appearance of glomus tumors: A retrospective study}

\author{
Alaa Eddin Obeid and Huda Al-Nasheet
}

DOI: https://doi.org/10.22271/ortho.2020.v6.i41.2420

\section{Abstract}

Background: The glomus tumor is a rare neoplasm and can be easily misdiagnosed. Patients with glomus tumor may present nonspecific symptoms such as long-term pain, temperature intolerance, and history of injury. It is common for such patients to be examined by physicians from various specialties such as orthopedics, family medicine or plastic surgery. They may undergo multiple imaging studies such as plain film X-ray, ultrasonography, or magnetic resonance imaging depending on the location of the nodule.

Objective: In this paper we present the first study in the Gulf Cooperation Council (GCC) region to address a retrospective institutional review of all ultrasonography studies of glomus tumors in a single medical center in the Kingdom of Bahrain between January 2013 and December 2018.

Results: Out of 31 patients with glomus tumors, 11 patients underwent an ultrasonography imaging study. The sex ratio (male: female) in the group of 11 patients was $0.56: 1$. 63.63\% (7/11) of the ultrasonography requests were done by orthopedic surgeons, whereas $27.27 \%(3 / 11)$ were requested by a primary care physician (PCP), and $9.09 \%(1 / 11)$ of the patients were referred by an emergency physician. Glomus tumors were more common in patients aged 30-39 years and 50-54 years with a mean age of (mean $\pm \mathrm{SD}, 47.818 \pm 12.408)$ years. Ultrasonography results showed that $100 \%(11 / 11)$ were hypoechoic. The majority of the studies showed $90.90 \%$ (10/11) with a well-defined border. Doppler US showed that $72.72 \%(8 / 11)$ had visible hypervascularization in the tumor, $18.18 \%(2 / 11)$ had moderate visible blood in the tumor, and $9.09 \%(1 / 11)$ had no comments on vascularity in the report. The tumor size ranged from 2.2 to $6.5 \mathrm{~mm}$ (mean $\pm \mathrm{SD}, 4.081 \pm 1.470 \mathrm{~mm}) \times 1$ to $4 \mathrm{~mm}$ (mean $\pm \mathrm{SD}, 2.690 \pm 1.135$ $\mathrm{mm}) .90 .90 \%(10 / 11)$ of glomus tumors were located in the fingers. $90.90 \%(10 / 11)$ of the lesions were located in the left hand, whereas $9.09 \%(1 / 11)$ were located in the right hand and $9.09 \%(1 / 11)$ in the left toe.

Conclusion: The results of this study were similar to those of other studies described in the literature. A well-defined, hypoechoic lesion with a hypervascular mass in the nail bed were the most common ultrasonography findings associated with subungual glomus tumors.

Keywords: Glomus tumor, hand, neoplasm, fingers, ultrasonography

\section{Introduction}

Glomus tumors are rare and benign tumors ${ }^{[1,2]}$. They account for up to $5 \%$ of all soft tissue tumors of the hand ${ }^{[2]}$. Such vascular neoplasms arise from the glomus body, which is a contractile neuromyoarterial structure found in the reticular dermis ${ }^{[3]}$. The role of the glomus body is to adjust blood pressure and temperature by regulating blood flow within the cutis ${ }^{[3]}$. Patients present with the classic triad of symptoms: paroxysmal pain, localized tenderness, and sensitivity to cold temperatures ${ }^{[4]}$. For accurate diagnosis, clinicians may request imaging studies such as computed tomography (CT), magnetic resonance imaging (MRI), and ultrasonography (US) ${ }^{[5,6]}$. In such cases, ultrasonography can be the better option, considering the time and cost required ${ }^{[5,6]}$. The aim of this study is to present the preoperative ultrasonography characteristics of pathologically confirmed glomus tumors in a single medical center in the Kingdom of Bahrain.

\section{Methods}

A list of patients with confirmed histopathological diagnosis of glomus tumor $(\mathrm{N}=31$ patients) between January 2014 and December 2019 was generated via SNOWMED codes using I-SEHA, which is the official EMR (Electronic Medical Record) adopted at the hospital. 
We looked into the preoperative ultrasonography reports of those patients, identifying 11 patients with ultrasonography imaging studies done between January 2013 and December 2018. Data obtained from the patients' medical records included demographic information, pathological diagnoses, radiological reports, and outpatient clinic visit information.

\section{Results}

Out of 31 patients with glomus tumors, 11 patients underwent ultrasonography imaging. The sex ratio (male: female) in the group of 11 patients was $0.56: 1$ (Figure 1). 63.63\% (7/11) of the ultrasonography requests were done by orthopedic surgeons, whereas $27.27 \%(3 / 11)$ requested a primary care physician (PCP), and $9.09 \%$ (1/11) of the patients were referred by an emergency physician. Glomus tumors were more common in patients aged 30-39 years and 50-54 years with a mean age of (mean $\pm \mathrm{SD}, 47.818 \pm 12.408$ ) years (Figure 2). Ultrasonography results showed that 100\% (11/11) were hypoechoic. The majority of the studies showed $90.90 \%(10 / 11)$ with a well-defined border. Doppler US showed that $72.72 \%(8 / 11)$ had visible hypervascularization in the tumor, $18.18 \%(2 / 11)$ had moderate visible blood in the tumor, and $9.09 \%(1 / 11)$ had no comments on the vascularity in the report. The tumor size ranged from 2.2 to $6.5 \mathrm{~mm}$ (mean $\pm \mathrm{SD}, 4.081 \pm 1.470 \mathrm{~mm}) \times 1$ to $4 \mathrm{~mm}$ (mean $\pm \mathrm{SD}$, $2.690 \pm 1.135 \mathrm{~mm}) .90 .90 \%(10 / 11)$ of glomus tumors located in the fingers. $90.90 \%(10 / 11)$ of the lesions were located in the left hand, whereas $9.09 \%(1 / 11)$ were located in the right hand and $9.09 \%(1 / 11)$ in the left toe. The diagnostic results of glomus tumors by Doppler ultrasonography are summarized in Table 1. The classic ultrasonography findings of glomus tumors are shown in Figures 3 and 4.

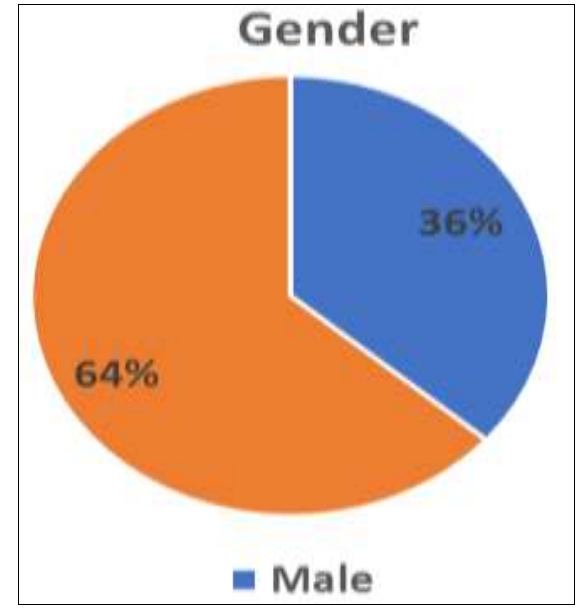

Fig 1: Gender distribution of patients with Glomus Tumor

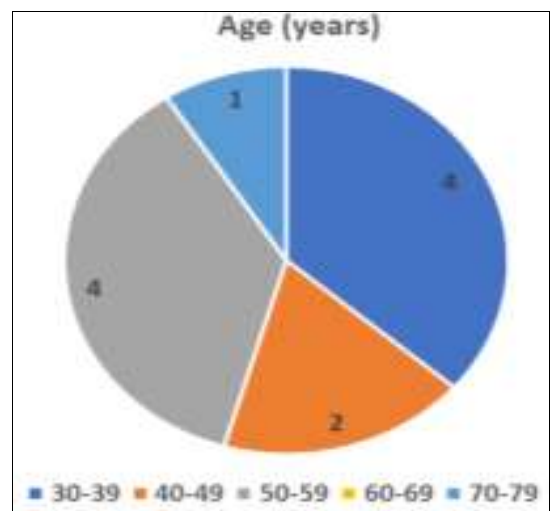

Fig 2: Age groups of patients with Glomus Tumor

Table 1: The diagnostic results of Glomus Tumors by Doppler ultrasonography $(\mathrm{n}=11)$

\begin{tabular}{|c|c|c|c|c|c|}
\hline Case No. & Size (mm) & Size (mm) & Margin & Echogenecity & Vascularity \\
\hline 1 & 6 & 5 & Well Defined & Hypoechoic & Hypervascular \\
\hline 2 & 3 & 3 & Well Defined & Hypoechoic & Hypervascular \\
\hline 3 & 4.8 & 3.1 & Well Defined & Hypoechoic & Hypervascular \\
\hline 4 & 5 & 3 & Well Defined & Hypoechoic & Hypervascular \\
\hline 5 & 6.5 & 4 & Well Defined & Hypoechoic & Mild Vascularity \\
\hline 6 & 2.2 & 2.8 & Well Defined & Hypoechoic & N/A \\
\hline 7 & 4 & 1 & N/A & Hypoechoic & Hypervascular \\
\hline 8 & 5 & 2 & Well Defined & Hypoechoic & Hypervascular \\
\hline 9 & 3 & 2 & Well Defined & Hypoechoic & Hypervascular \\
\hline 10 & 2.4 & 1.5 & Well Defined & Hypoechoic & Hypervascular \\
\hline 11 & 3 & 2.2 & Well Defined & Hypoechoic & Mild Vascularity \\
\hline
\end{tabular}

\section{Discussion}

Glomus tumors are difficult to diagnose because patients usually present with non-specific symptoms such as pain and sensitivity to cold ${ }^{[7]}$. Although its etiology is still unknown, the cause may be attributed to various factors such as past injury, trauma, sex, age, and genetics ${ }^{[8]}$. Glomus tumors can occur in various parts of the body; the most common site reported in the literature is solitary extra digital distribution along the upper extremity; the finger or toe were the most common sites reported in the literature ${ }^{[8]}$. The use of highfrequency ultrasound in the preoperative examination of glomus tumors can accurately locate the position and show the characteristics of the nodule in real time ${ }^{[6]}$. Chiang et al. described in their study 11 cases of the tumor with rich intratumoral blood flow signal with ultrasonography ${ }^{[9]}$. Not all glomus tumors were rich in blood; a study done by Zhina et al. shows little visible blood and no intratumoral blood flow in their study samples ${ }^{[6]}$. Wortsman and Jemec reported seven cases with hypoechoic lesions with clear borders ${ }^{[10,11]}$. The exact internal hemodynamics of glomus tumors are still underreported in the literature, and their influence on surgical treatment and prognosis needs to be further assessed ${ }^{[6,8]}$. 


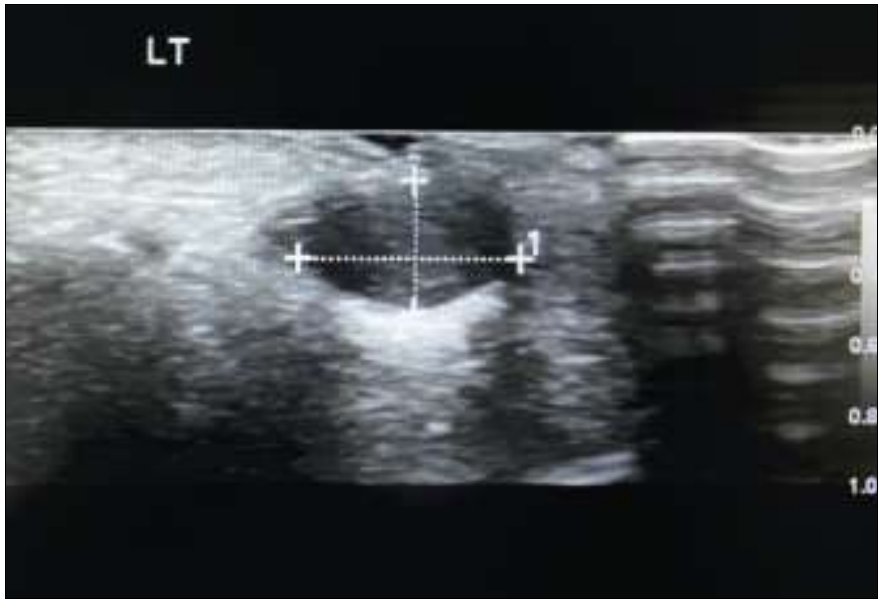

Fig 3: US image shows well defined, rounded and hypoechoic lesion measuring $6.5 \times 4 \mathrm{~mm}$ in size located beneath the nail of the left second toe causing focal scalloping of the underlying distal phalynx

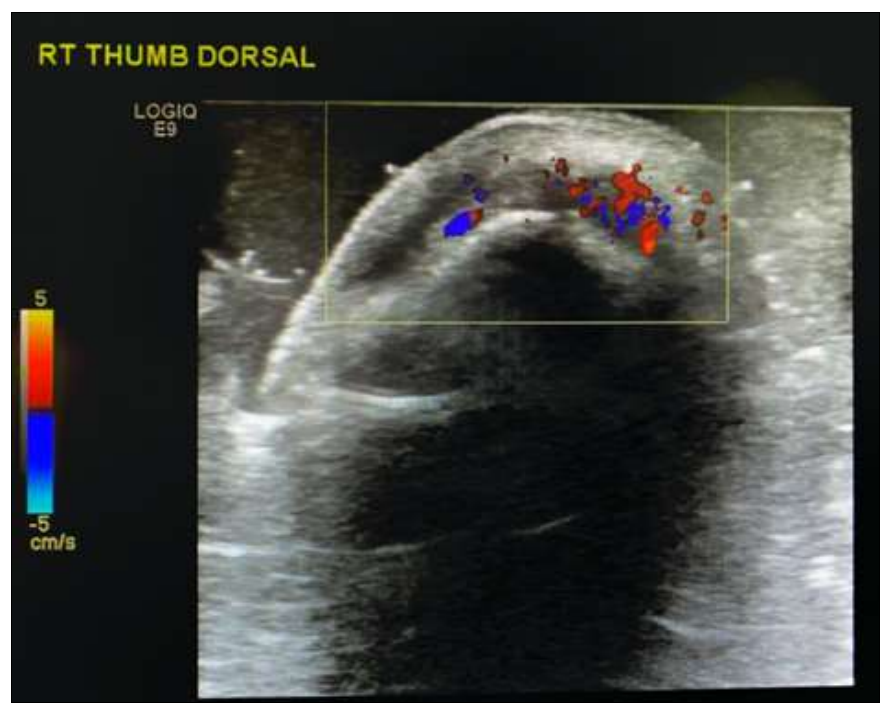

Fig 4: US image shows lobulated, solid appearing and hypervascular mass dorsal to the base of the distal phalynx of the right thumb

\section{Conclusion}

The results of this study were similar to other studies described in the literature. A well-defined, hypoechoic lesion with a hypervascular mass in the nail bed were the most common ultrasonography findings associated with subungual glomus tumors. Although the sample size of this study is small and considering the glomus tumor low incidence rate, we believe that understanding the common ultrasonography features may be helpful in the diagnosis of such nodules.

\section{References}

1. Schiefer TK, Parker WL, Anakwenze OA, Amadio PC, Inwards CY, Spinner RJ. Extradigital glomus tumors: a 20-year experience. InMayo Clinic Proceedings Elsevier 2006;81(10):1337-1344.

2. Senhaji G, Gallouj S, El Jouari O, Lamouaffaq A, Rimani M, Mernissi FZ. Rare tumor in unusual location-glomus tumor of the finger pulp (clinical and dermoscopic features): a case report. Journal of medical case reports 2018;12(1):196.

3. Macharia C, Nthumba PM. Glomus tumor presenting as complex regional pain syndrome of the left upper limb: a case report. Journal of medical case reports 2015;9(1):293.

4. Stewart DR, Sloan JL, Yao L, Mannes AJ, Moshyedi A, Lee CCR, Legius E. Diagnosis, management, and complications of glomus tumours of the digits in neurofibromatosis type 1 . Journal of medical genetics 2010;47(8):525-532.

5. Drapé JL. Imaging of tumors of the nail unit. Clinics in podiatric medicine and surgery 2004;21(4):493-511.

6. Fan Z, Wu G, Ji B, Wang C, Luo S, Liu Y. Color doppler ultrasound morphology of glomus tumors of the extremities. Springerplus 2016;5(1):1319.

7. Santoshi JA, Kori VK, Khurana U. Glomus tumor of the fingertips: A frequently missed diagnosis. Journal of Family Medicine and Primary Care 2019;8(3):904.

8. Morey VM, Garg B, Kotwal PP. Glomus tumours of the hand: review of literature. Journal of clinical orthopaedics and trauma 2016;7(4):286-291.

9. Chiang YP, Hsu CY, Lien WC, Chang YJ. Ultrasonographic appearance of subungual glomus tumors. Journal of Clinical Ultrasound 2014;42(6):336340.

10. Wortsman X, Jemec GB. Role of high-variable frequency ultrasound in preoperative diagnosis of glomus tumors. American journal of clinical dermatology 2009;10(1):23-27.

11. Fornage BD. Glomus tumors in the fingers: diagnosis with US. Radiology 1988;167(1):183-185.

12. Chisci E, De Donato G, Setacci F, Perulli A, Galzerano G, Setacci C. A rare vascular tumour with distinctive clinical findings. Journal of Cardiovascular Surgery 2008;49(2):241. 